\title{
Studies on friction behaviour of aluminium AA4032 alloy during forging using ring compression test
}

\author{
Desalegn Wogaso ${ }^{1 *}$, Mohammed Hamda ${ }^{2}$ \\ ${ }^{1 *}$ Department of Mechanical Engineering, Addis Ababa Institute of Technology, Addis Ababa University, Addis Ababa, ETHIOPIA \\ ${ }^{2}$ Department of Mechanical Engineering, Adama Science \& Technology University, Adama, ETHIOPIA \\ "Corresponding Author: e-mail: desalegnalem@gmail.com, Tel +2519161014035 \\ ORCID iDs: https://orcid.org/0000-0002-0476-656X (Wogaso), https://orcid.org/0000-0001-8093-9955 (Hamda)
}

\begin{abstract}
In metal forming, friction has a negative effect on the deformation load \& energy requirements, homogeneity of metal flow, quality of formed surfaces, etc.; however, its effect can be reduced through the use of proper lubricants. Mostly, in industrial applications, selection of proper lubricant for specific material is challenging and quantification of magnitude of friction at diework piece interface is essential. Hence, for metallic alloys, a realistic friction factor is needed to be known and used at the diework piece interface for better control of deformation process. Thus, this research, generally, aims at experimental investigation of the friction behavior of aluminum AA4032 alloy and selection of suitable lubricant for its effective processing using ring compression test and finite element (FE) simulations. Meanwhile, the effect of metal surface conditions and different lubricants namely palm oil, grease, emulsion oil and dry conditions on the friction behaviour has been evaluated. A commercial FEM software, DEFORM 3D, is used to analyze the flow of metal, determine the geometry changes of the specimen and generate friction calibration curves. The results revealed that the nature of metal surface and lubricating conditions have significantly affected the metal flow pattern, deformation load requirement, induced effective stress and strain, and geometry of the metal. The friction factor at die-work piece is determined for different lubricating conditions. Among lubricants employed, palm oil is found to be suitable and effective for industrial processing of aluminium AA4032 alloy, specifically for forging. The FE simulation results are in a good agreement with the experimental one.
\end{abstract}

Keywords: Friction factor, surface roughness, ring compression test, lubricants, FE simulation

DOI: http://dx.doi.org/10.4314/ijest.v13i3.3

Cite this article as:

Wogaso D., Hamda M. 2021. Studies on friction behaviour of aluminum AA4032 alloy during forging using ring compression test. International Journal of Engineering, Science and Technology, Vol. 13, No. 3, pp. 23-36. doi: 10.4314/ijest.v13i3.3

Received: July 16, 2021; Accepted: August 18, 2021; Final acceptance in revised form: September 11, 2021

\section{Introduction}

Metal forming processes, such as forging, is most commonly used industrial practices by which metal is pressed, pounded or squeezed under great pressure into high strength parts (Semiatin, 1998). During forging process, the work piece is placed between upper and lower die, and made to deform under high compressive pressure provided by the power module when the two dies move towards each other. Mechanical parts obtained through forging are very common in industrial practice, and they are stronger than an equivalent cast part or machined part. This is because the microstructure of the material is continuous throughout the part, giving rise to a piece with improved strength characteristics. 
In metal forming, friction significantly affects the shape of the work piece as reported by Narayanasamy and Pandey (1997). When the workpiece made contact with the die, it is deformed mainly under the pressure normal to the interface, and at the same time the work piece flows in the tangential direction as well. Such tangential flow depends on the friction condition of the diework piece interface. It would lead to higher equivalent stress, which reduces the workability of the metal and leads to premature failure. Thus, to obtain products with the desired characteristics, the friction condition on the die-work piece interface is required to be controlled. As the ease of metal flow is key to achieving die fill in forging, common industrial practice made to reduce interface friction is to use lubricants. When the two surfaces are separated by a lubricant layer, the asperities of the surfaces will not interact each other, as a result metal can easily flow between die and work piece interface. Furthermore, proper and adequate lubrication with a suitable lubricant is essential to reduce this interface friction. Rajesh and Siva-Prakash (2013) conducted experimental study to determine the friction factor under different lubricating conditions. The result showed that presence of lubricant at the interface between the tool and work piece reduces the friction coefficient. Wogaso et al. utilized ring compression test and finite element (FE) simulations to investigate the frictional behavior of powder metallurgical $\mathrm{Al}-4 \% \mathrm{Cu}$ preforms under different initial relative densities and lubricating conditions (Wogaso et al., 2014). They showed use of appropriate lubricants has reduced the interface friction. Shahriari et al. (2011) also conducted experimental study and FE simulations to determine effect of lubricating conditions and temperature on the friction coefficient during hot forging. They revealed that the interfacial friction is significantly dependent on the temperature and type of lubricants used.

Most importantly, metal forging introduces plastic deformation and an increase in a new surface area that causes most of lubricants squeezed out, resulting in boundary lubrications to be present at critical locations, even where a thick layer of lubricant is sprayed initially as summarized by Peterson and Ling (1966). The lubricating condition varies a lot during metal forming processes. Therefore, one has to consider the working conditions in order to select most proper lubricant. Under high pressures and reductions, the lubricant film often breaks down and causes poor metal flow and wear of the forming tools. In addition, Isogawa et al. (1992) suggested that it is not economically practicable or viable to test large number of lubricants in the production shops, since any failure in lubrication may result in huge loss of money and time. Performance of the lubricants cannot be predicted accurately. This again leads to wrong usage of lubricants and subsequently losses. Therefore, it is essential to conduct the friction measurement test and find the lubricity of the lubricants in a laboratory setup under actual production conditions.

In contrast to existing techniques of application mode of lubricants, it is hypothesized that coefficient of friction value for each material must be known in a given metal forming processes. Sofuoglu and Rasty (1999) utilized ring compression test to evaluate the effect of different factors namely material properties, strain rate sensitivity, and barreling on friction behaviour and revealed that the friction calibration curves are notably influenced by material properties and testing conditions, and every material possesses its own distinctive friction calibration curves. Camacho et al. (2013) also studied interface friction in metal forming of industrial alloys including steel, stainless steel, copper alloy, titanium alloy and nickel alloy. Ring compression test was used in order to determine friction calibration maps for different metallic alloys that are typically used in industrial practice of metal forming. Furthermore, the differences and similarities in the behavior observed are evaluated for all materials. It was concluded that the importance of using a friction calibration map for each material.

Nowadays, environmental issues are of great importance. Lately, lubricants are formulated from heavily compounded chemically active minerals and frequently different types of additives are used that are not environmentally friendly as stated by Cisson et al. (1996), and their production process produces some environmentally hazardous chemical components. However, the scientific world is now looking for alternative lubricants that are more environmentally friendly. Consequently, there was considerable motivation to find an alternative lubrication method, especially for cold forging of aluminum alloys. Since aluminum AA302 alloy is characterized by low coefficient of thermal expansion and better wear resistance, it has been widely used for the production of forged engine pistons; however during forging, industries traditionally use vegetable oils and shop grease as a lubricant (Bay, 1994).

Considering the hypothesized relationship between interface friction and material friction calibration curves, the overall goal of this research is to investigate the frictional behavior and select suitable lubricant for cold working of aluminium AA4032 alloy by using ring compression test and FE simulations. Specifically, the effect of surface roughness and lubricating conditions on metal flow are investigated. Through the use of a constant surface roughness value, the effect of different lubricating conditions on the deformation behavior has been evaluated. Integrated approach of ring compression test and FE simulation have been employed to investigate the friction behaviour of the aluminum AA4032 alloy metal during forging.

\section{Experimental Details}

\subsection{Ring specimen preparation}

For the current research, aluminium AA4032 alloy metal was considered for investigation as it has got broad range of applications in major industries like automotive, aerospace, building construction, etc due to its unique combination of properties. Chemical composition of wrought aluminum AA4032 alloy was examined using mass spectrometer and depicted in Table 1.

Table 1. Chemical composition of aluminum AA4032 alloy

\begin{tabular}{|l|l|l|l|l|l|l|l|l|l|l|c|}
\hline $\mathrm{Al}$ & $\mathrm{Si}$ & $\mathrm{Fe}$ & $\mathrm{Cu}$ & $\mathrm{Mn}$ & $\mathrm{Mg}$ & $\mathrm{Zn}$ & $\mathrm{Ni}$ & $\mathrm{Cr}$ & $\mathrm{Pb}$ & $\mathrm{Sn}$ & Element \\
\hline 84.94 & 12.16 & 0.03 & 0.89 & 0.02 & 0.98 & 0.009 & 0.892 & 0.029 & 0.03 & 0.011 & $\mathbf{\%}$ \\
\hline
\end{tabular}


The ring specimens were prepared by machining aluminum AA4032 alloy metal to standard ring compression geometry of outer diameter: inner diameter: height ratio of 6:3:2 $(24: 12: 8 \mathrm{~mm})$, respectively. A 6:3:2 geometry ratio was selected for the study for the fact that it minimizes the strain rate sensitivity of the metal as reported elsewhere (Dutton et al., 1999). The required surface roughness of each ring specimens was imparted using controlled grinding and polishing techniques for different experimental conditions. The geometry of the ring specimen before compression test is illustrated in Fig. 1. The tests were conducted on different specimens for each lubricating and surface roughness conditions, and to get accurate results, each experiment was replicated three times.

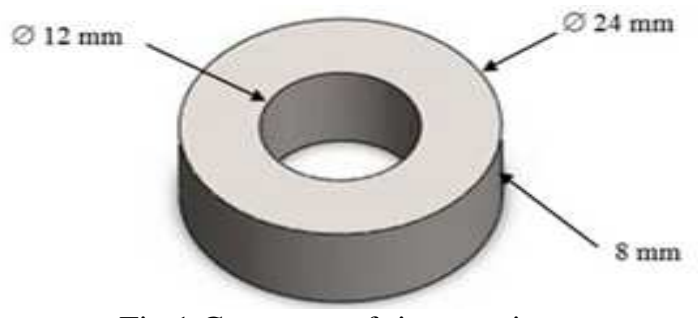

Fig.1 Geometry of ring specimen

\subsection{Imparting surface roughness}

Metal forming industries traditionally use metals with random surface roughness conditions. Selection of appropriate lubricant for the specific surface roughness is not easy. Thus, in this research, different surface roughness values of the metal were prepared and their corresponding interface friction factors were determined. Based on the result, suitable surface roughness of the specimen was selected to examine the effects of various lubricating conditions on the interface friction factor. Developing quantitative frictional value for AA4032 alloy metal under different lubricating condition is a direct demand for metal forming industries. Thus, to investigate the effect of surface roughness value on interface friction factor, roughness values of the specimen corresponding to $1.50 \mu \mathrm{m}, 2.50 \mu \mathrm{m}$ and $3.50 \mu \mathrm{m}$ in $\mathrm{R}_{\mathrm{a}}$ were considered. Roughness of $1.50 \mu \mathrm{m}$ (termed low surface roughness) was selected as it is typical of the work piece finish employed in most metal forming industries. Further, medium and larger roughness values of $R_{a}$, $2.50 \mu \mathrm{m}$ and $3.50 \mu \mathrm{m}$ (termed as medium and higher values) were employed and intended to simulate the effect of metal surface conditions on deformation behaviour. A comprehensive list of experimental conditions namely surface roughness values and lubricating conditions is depicted in Table 2. Figure 2 also shows photographs of ring specimens with different surface roughness conditions.

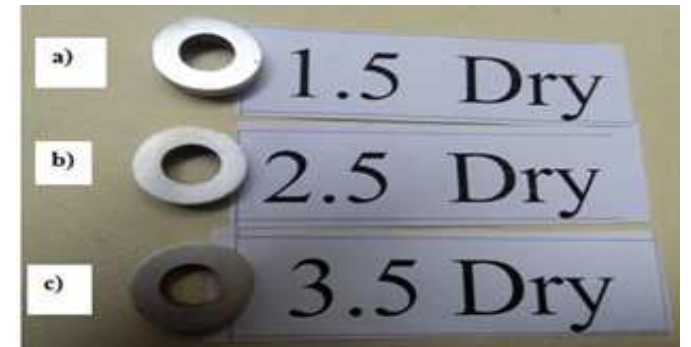

Fig.2 Photographs of ring specimens with: a) $1.5 \mu \mathrm{m}$ surface roughness value, b) $2.5 \mu \mathrm{m}$ surface roughness value and c) $3.5 \mu \mathrm{m}$ surface roughness value.

To develop the required surface roughness on the specimens, a standard flat grinder and different grit size emery papers were used. The surface of the specimens was polished using different waterproof abrasive paper of grit size 60, 120, 240, 320, 360 and 380 to obtain the required values. Employing repeated passes of the specimens over the selected emery papers, the required surface roughness values of $R_{a}=1.50 \mu \mathrm{m}, 2.5 \mu \mathrm{m}$ and $3.50 \mu \mathrm{m}$ were prepared. To maintain consistence in the values, all grinding passes were limited to a single direction and equal number. Waterproof abrasive paper of 380 grit size was used to reduce surface profile marks created during machining. Lastly, the metal surface roughness was measured with a surface roughness tester (SRT-6210 model type).

Table 2 Experimental conditions

\begin{tabular}{|c|c|c|}
\hline $\begin{array}{l}\text { Specimen } \\
\text { Geometry }\end{array}$ & $\begin{array}{l}\text { Lubricating } \\
\text { condition }\end{array}$ & $\begin{array}{l}\text { Surface roughness } \\
\text { values }(\mu \mathrm{m})\end{array}$ \\
\hline \multirow{6}{*}{$\begin{array}{l}\text { OD }: \text { ID }: H \\
(24: 12: 8)\end{array}$} & \multirow{3}{*}{ Dry } & 1.50 \\
\hline & & 2.50 \\
\hline & & 3.50 \\
\hline & Palm oil & \multirow{3}{*}{$\begin{array}{l}\text { at } 1.5 \mu \mathrm{m} \text { surface } \\
\text { roughness value }\end{array}$} \\
\hline & Grease & \\
\hline & Emulsion oil & \\
\hline
\end{tabular}




\subsection{Lubricants used}

Lubricants employed for this study were mainly oil-based (palm oil), grease, emulsion oil and dry conditions. Using the ring compression test, the performance of these lubricants during cold forging of aluminum AA4032 alloy was evaluated. Selection of the suitable lubricants with lower friction factor for forging of AA4032 alloy was determined experimentally by examining dimensional changes of internal diameter (\%) and height reduction (\%) of ring specimens. In addition, ring compression test and FE simulation approach were integrated to evaluate friction behavior of the metal.

\subsection{Ring compression tests}

The ring compression test was carried out between two parallel flat mirror finished open dies of hydraulic press with capacity 3000 $\mathrm{kN}$ at a ram speed of $0.25 \mathrm{~mm} / \mathrm{s}$. The non-related parameters were all kept at constant values. A summary of the conditions used to investigate the friction factor for each surface roughness and lubricating condition is depicted in Table 2 . To verify the consistency of the results, three replications were carried out under each experimental condition. The height reduction and inner diameter change of ring specimens with respect to various surface and lubricating conditions were plotted and compared with that of Male and Cockcroft friction calibration curves (Male and Cockcroft, 1965).

\subsection{Evaluation of metal flow}

In ring compression test, the specimen was assumed to deform in a uniaxial state of stress condition. Determination of effective stress and strain values is essential, particularly for forming involving large amount of plastic deformation. After the ring compression tests were performed, the metal flow behaviour including engineering stress and strain, true stress and strain, strain hardening exponent and strength coefficient were determined. The computation of material properties namely strain hardening exponent and strength coefficient were made by taking the values of the true strain and true stress which represent the plastic flow of the material.

\subsection{Finite element simulations}

Finite element simulation of ring compression test was carried out using rigid-plastic deformation model. Modeling and analysis of metal forming processes have been specialized applications, and only a limited range of FE software which is capable of conducting the analysis. Hence, the selection of FE software is one of the dominant aspects of metal forming process analysis. Oh et al. (1991) validated the effectiveness of FE simulation using DEFORM software for its use in metal forming analysis. It is capable of handling different types of materials such as rigid plastic, elastic plastic and powder materials. Simulation of bulk forming processes with FE method is a powerful and effective tool for analyzing the metal forming processes.

In this study, the FE modeling of ring compression test was performed using commercial software, DEFORM 3D, and the model is illustrated in Fig. 3. An axisymmetric formulation of the specimen was considered during modeling; hence 3D modeling in Fig. 3 represents only one half of the ring specimen simulation.

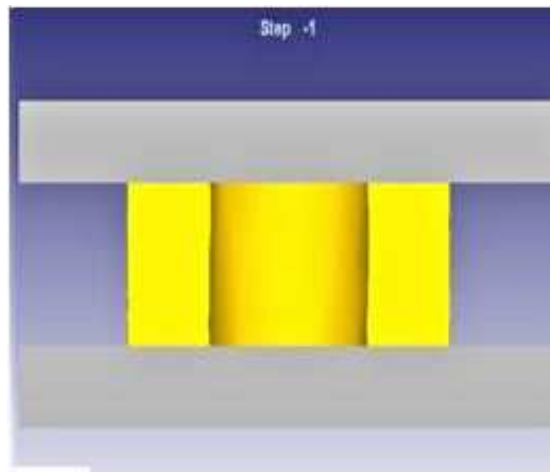

a)

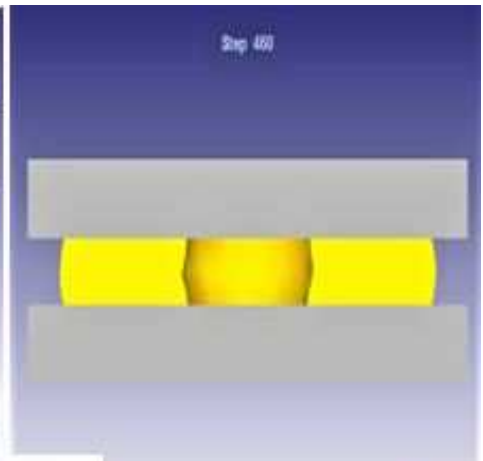

b)

Fig.3 FE method modeling of ring compression test (a) before deformation and (b) after deformation

In the methodology of FE simulation, as suggested by the Rao et al. (2009), the tetrahedral element type which reduces the number of iteration had been chosen and the specimen geometry was neither too fine meshed nor coarse meshed thereby long computational time and accuracy with unnecessary precision was minimized. Therefore, a tetrahedral nodded element of two thousand in number was selected to mesh the ring geometry. Selection of friction model is one of the key issues in FE modeling. Among these models, the one with higher accuracy is still unknown and controversial. However, Fereshteh et al. (2004) studied friction modeling using the physical simulation during bulk metal forming processes. Coulomb and constant friction models are the two most commonly used mathematical models for friction quantification in metal forming process. Coulomb model is mainly used in processes with low pressures, whereas constant friction model is adequate for processes where high effective strains and pressures prevail. De-Pierrie and Gurney (1974) also presented that the constant friction model is more realistic than the 
Coulomb's model in describing and quantifying the shear stresses in bulk forming processes. Therefore, in the FE modeling, constant friction model was chosen for various surface roughness and lubricating conditions since its simplicity seemingly indicates the material feature of plastic deformation.

\subsection{Determination of friction factor}

First attempt was made to determine the friction factor for various surface roughness and lubricating conditions by measuring the change in inner diameter and reduction in height of the ring specimens. The properties of AA4032 metal were determined by using compression test for different surface roughness and lubricating conditions, respectively. To determine the friction factor between the interface of the die and ring specimen, the friction calibration curve was standardized into plots that represent the deformation in the ring as it was compressed. The friction calibration curves were derived by using FE method software (DEFORM 3D) by incorporating the properties of material as input. As shown in Fig. 3, an axis-symmetric model was created using DEFORM 3D which is a commercial software and a product of Scientific Forming Technologies Corporation. The sizes of ring samples are same as the ones used in experiments. Series of simulations were run with same setup but different friction factors between die and ring specimen. Friction factors were varied between 0 and 1 . The height reduction and inner diameter changes at each step were measured and used for the determination of material properties and geometry changes of the ring specimens. The values of height reduction (\%) and change in inner diameter (\%) were used to generate friction calibration curves and mapped against a Male and Cockcroft friction calibration curves as shown in Fig. 4 in which each curve represents a distinct value of friction factor. The friction factor can be obtained simply by plotting percentage of height reduction and inner diameter change of ring specimen, and made to fit against Male and Cockcroft friction calibration curves.

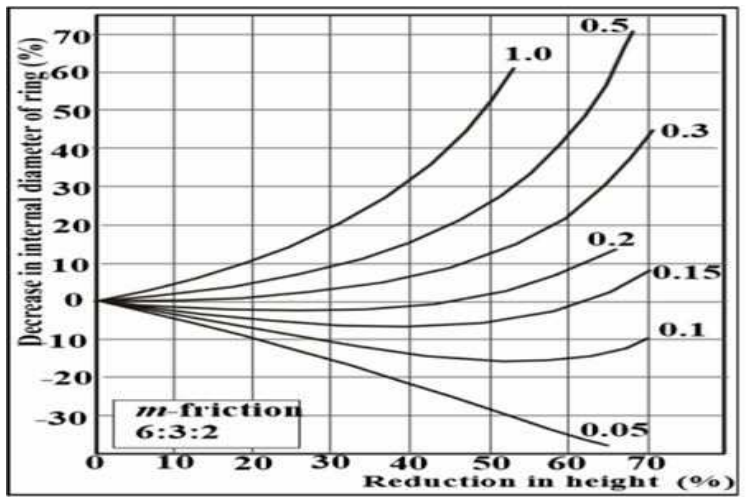

Fig.4 Male and Cockcroft friction calibration curve (Male and Cockcroft, 1965)

\section{Results and Discussions}

\subsection{Determination of material properties}

The experimental result of geometry changes of ring specimens in terms of outer diameter, inner diameter and height reduction with respect to deformation load was determined. Photographs of deformed ring specimens with different surface roughness values and lubricating condition are also shown in Fig. 5.

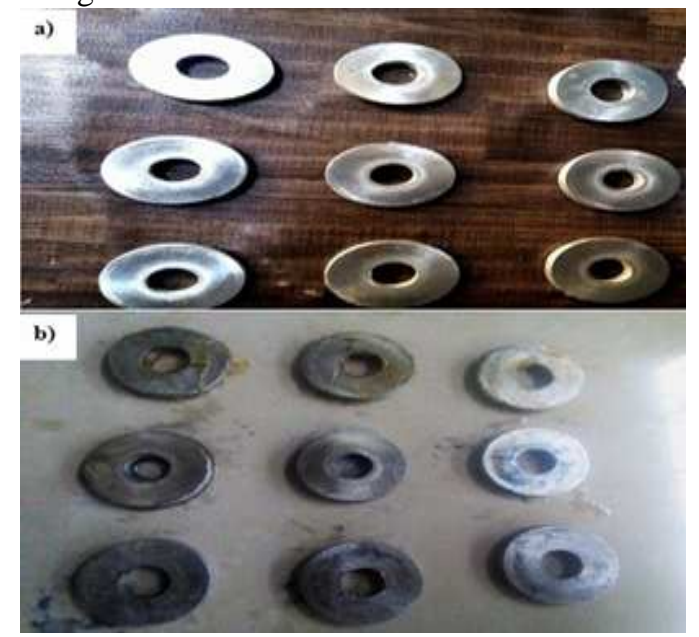

Fig.5 Photographs of deformed ring specimens at fracture load for various surface roughness and lubricating conditions a) Dry condition and b) Lubricated conditions 
It is clearly observed that the deformed specimens' surface show different texture for different lubricating conditions. At fracture detected deformation, it was observed that the contraction of inner diameter increases with increase in the surface roughness value, whereas, height reduction decreases with increase in the roughness. This is due to increase in roughness (asperity peaks) on the work piece which restricts the metal flow at the die-work piece interface. Also, for various lubricating conditions, the inner diameters of ring specimen lubricated with grease and emulsion were shown more contraction than the inner diameter of ring specimen lubricated with palm oil. This observation is also in agreement with findings obtained by Male and Cockcroft (1965).

The flow stress curves generated from the ring compression test with different surface roughness and lubricating conditions, and are illustrated in Fig. 6. In the flow stress curves, there is an apparent shape change in their last regions with respect to variation in the surface roughness values and lubricating conditions. On the other hand, initial regions seem to be similar. Considering various lubricating condition, the amount of plastic deformation (induced strain level) varies with type of lubricants employed ignoring the effect of specimen's surface roughness. With palm oil, higher reduction in the height (\%) is observed and it might be due to introduction of uniform flow of metal during deformation. The general flow stress equation was obtained by fitting the properties of material, specifically, strain hardening exponent and strength coefficient against Ludwik equation $\left(\sigma=K \varepsilon^{n}\right)$. Accordingly, the strain hardening exponent and strength coefficient values for aluminium AA4032 alloy metal is obtained by taking the average values for all conditions. The flow-stress equation thus obtained as $\sigma=678 \varepsilon^{0.33}$ for the specific material under given experimental condition. In specific terms, the $\mathrm{n}$ and $\mathrm{K}$ values are slightly dependent on the loading conditions. Different friction loading conditions resulted in variations of $\mathrm{n}$ and $\mathrm{K}$ values which determines the amount of plastic deformation of the metal. The result obtained shows that lower frictional conditions resulted in more amount of plastic deformation, i.e. higher values of $n$.

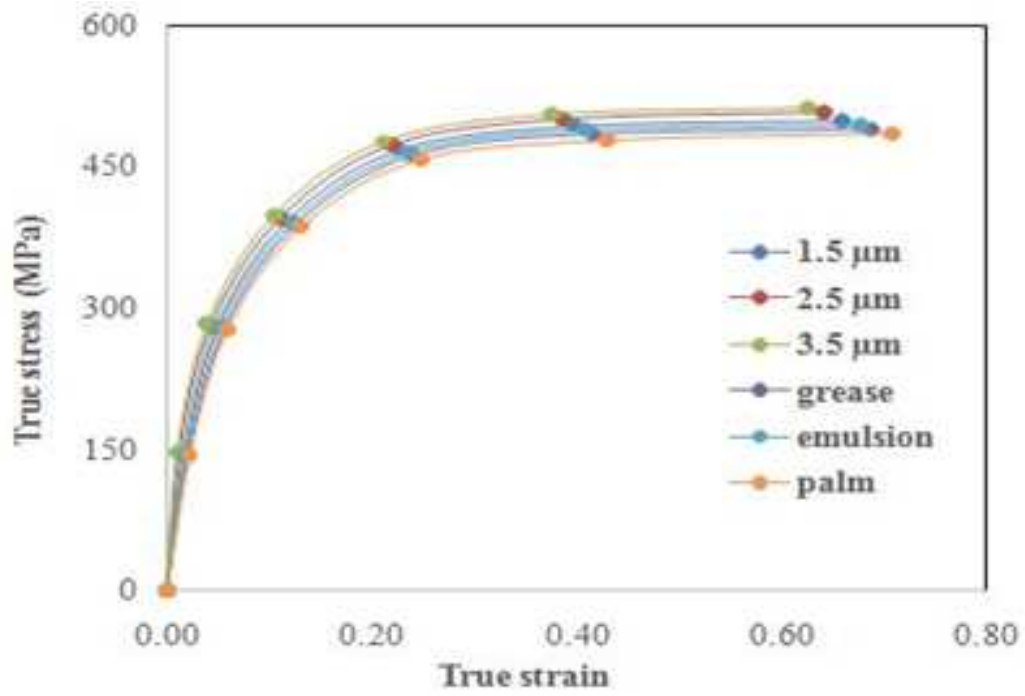

Fig.6 Flow stress curve for AA4032 alloy specimen with different surface roughness deformed at various lubricating conditions

The determined strain hardening exponent and strength coefficient are in agreement with findings of Fereshteh-Saniee and Fatehi-Sichani (2006). The determined values are mainly used to assess metal behavior in both uniaxial tension and compression at room temperature. The larger the strain hardening exponent value, the more the material can deform before instability. Calculated effective strains and stresses at each deformation load during ring compression test for specimens with various surface roughness and lubricating conditions is examined.

\subsection{Effect of surface roughness on friction factor and deformation load}

The friction factor for specimens with different surface roughness values namely $1.50 \mu \mathrm{m}, 2.50 \mu \mathrm{m}$ and $3.50 \mu \mathrm{m}$ at dry condition is presented in Fig. 7. It was obtained as 0.50, 0.53 and 0.55 for specimens with surface roughness values of $1.50 \mu \mathrm{m}, 2.50 \mu \mathrm{m}$ and $3.50 \mu \mathrm{m}$, respectively. It is evident that higher friction factor value is recorded for specimen with higher surface roughness, 3.50 $\mu \mathrm{m}$. This increase in friction factor is the result of the increased asperity contact at the die-work piece interface. As the surface roughness of the test specimen increases, similar rise in the magnitude of the surface asperities occurs. This rise in asperity peaks leads to restricted flow of at the die-work piece interface. As a result, the interfacial friction factor between the die and specimen increases further. In addition, it was observed that the contraction of inner diameter was increased with increase in the surface roughness value, whereas, reduction in height was decreased with increase in the roughness. 


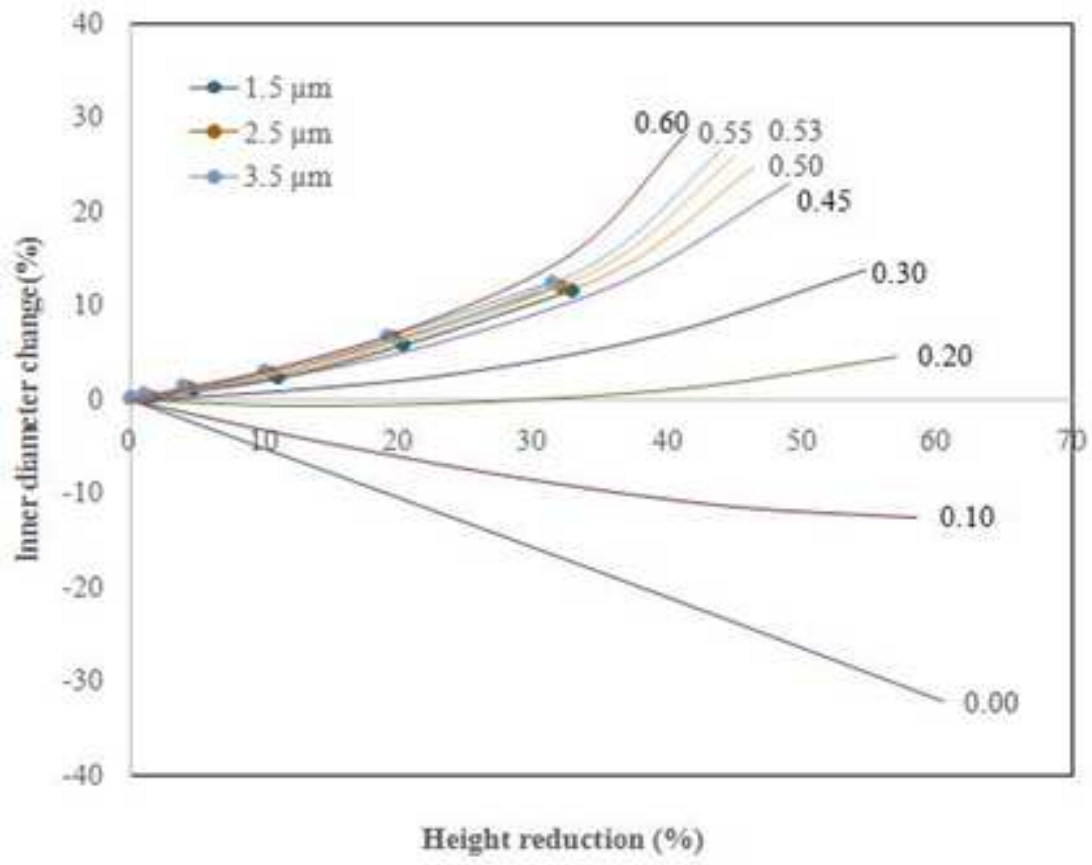

Fig.7 Friction calibration curves for different surface roughness values at dry condition

Figure 8 shows the relationship between surface roughness, friction factor and deformation load requirement for forging AA4032 aluminum alloy. At the onset of fracture, the average deformation load requirement for ring specimens is obtained to be $329 \mathrm{kN}$, $327.67 \mathrm{kN}$ and $326 \mathrm{kN}$ with respect to specimen's surface roughness values, respectively.
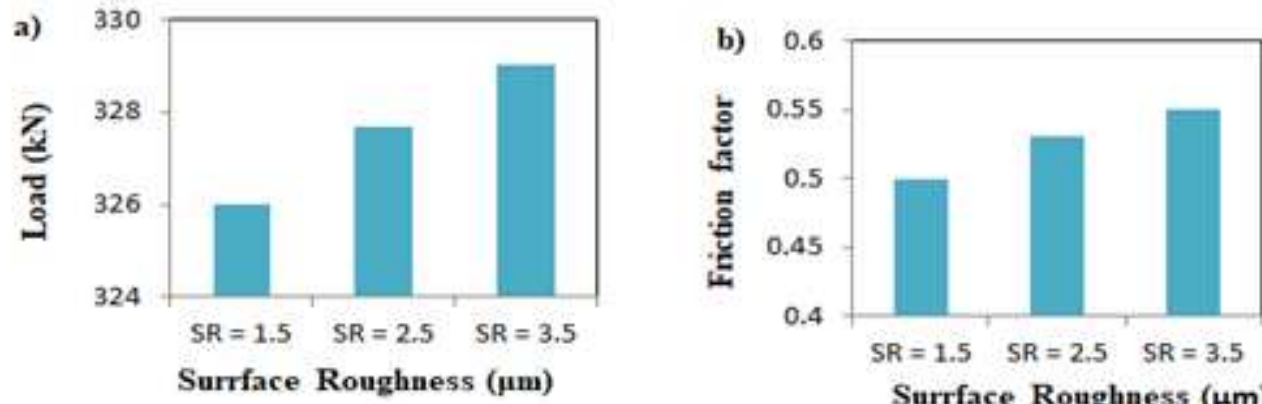

Surrface Roughness $(\mu \mathrm{m})$

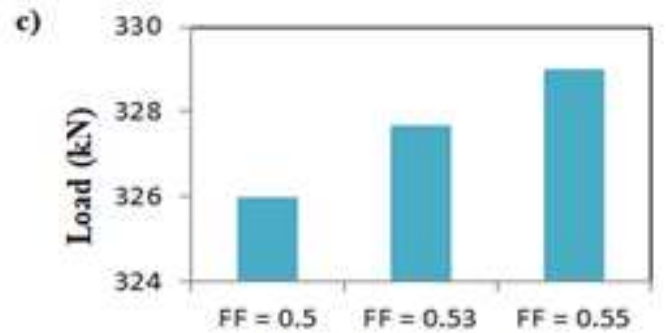

Friction factor (FF)

Fig.8 Relationship between three factors a) effect of surface roughness on deformation lad, b) effect of surface roughness on friction factor and, c) Effect of friction factor deformation load

\subsection{Effect of friction on effective strain and stress at dry condition}

As a result of the relationships identified between friction factor and specimen's surface roughness, it is clear that metal flow is significantly influenced by surface roughness of specimens. Hence, induced strain and stress characterize the amount of metal flow between die-work piece interfaces. Specifically, the induced strain is obtained from the geometry measurements for each specimen with different surface roughness. Increase in induced strain is observed with respect to lower surface roughness value and/or lower friction factor, and it indicates that relatively more metal flows at interface between die-work pieces during forming; while the amount of metal flow in specimen with higher surface roughness is relatively low and restricted. Moreover, the relationship 
between friction factor and induced effective strain and effective stress at 50\% height reduction is shown in Fig. 9a and b. An increase in friction factor results in increase in effective stress and on the other hand, the maximum effective stress is observed at lower values of effective strain.

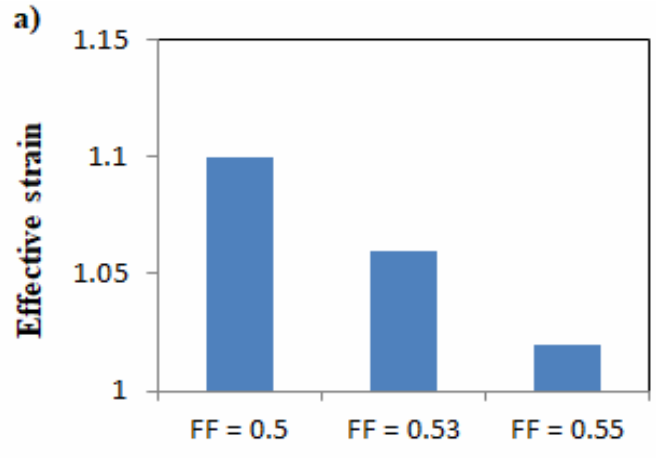

Friction factor (FF)

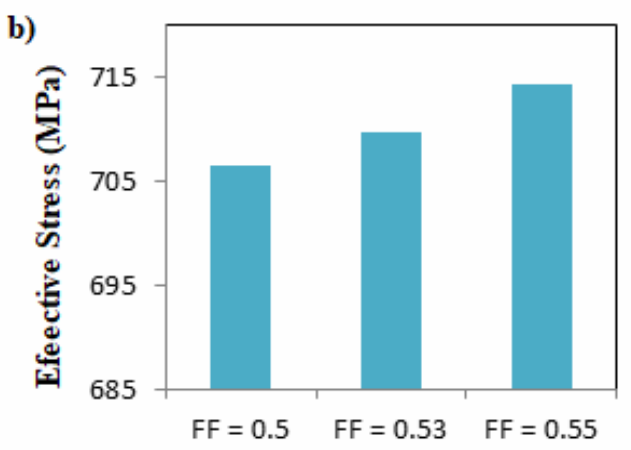

Friction factor (FF)

Fig.9 Effect of friction on a) effective strain, b) effective stress, at dry condition

During deformation, specimens with lower surface roughness and/or friction factor undergo more amount of plastic deformation. This is due to increase in reduction of the material with the strain induced which allows metal flow with comparable lower restriction at the die-work piece interface. Using the above concepts, effects of surface roughness on interface friction, i.e. $1.5 \mu \mathrm{m}$ with friction factor of 0.5 appears to be suitable roughness condition for dry forming, as it allows more amount of metal flow between die-work pieces interface.

\subsection{Friction factor for lubricating conditions}

Figure 10 shows effect of lubricants on interface friction factor for specimen with surface roughness value of $1.5 \mu \mathrm{m}$. The friction factor for the palm oil, grease and emulsion oil lubricants are found to be $0.30,0.35$ and 0.45 , respectively. Further, metal flow can be easily quantified through measurement of true strain from the reduction in height of the compressed specimens, and used as a means to compare the effects of lubricant on the flow of metal. When various lubricants are used, strain increases as compared to dry conditions which mean the metal undergo more amount of deformation. It is also observed in the Fig. 10 that true strain increases with decrease in friction factor at different lubricating conditions. While, using palm oil as lubricant, the maximum true strain value, 0.71 , is obtained. Similarly, with grease and emulsion oil, the maximum true strain is decreased to 0.69 and 0.68 , respectively. Among selected lubricants, palm oil is obtained as best most appropriate lubricant for metal forming of Al-alloy due to its better capability to reduce sticking force at the interface. Moreover, the inner diameters of ring specimen lubricated with grease and emulsions are more contracted than with lubricated with palm oil.

\subsection{Effect of friction on deformation load requirement, effective stress and strain for lubricating conditions}

The effects of friction factor on the deformation load requirements for AA4032 alloy during ring compression test with lubricating conditions of palm oil, grease and emulsion oil is presented in Fig. 11. In order to quantify the influence of friction factor on the deformation load, final deformation loads with respect to various lubricating conditions are considered at fracture deformation state.

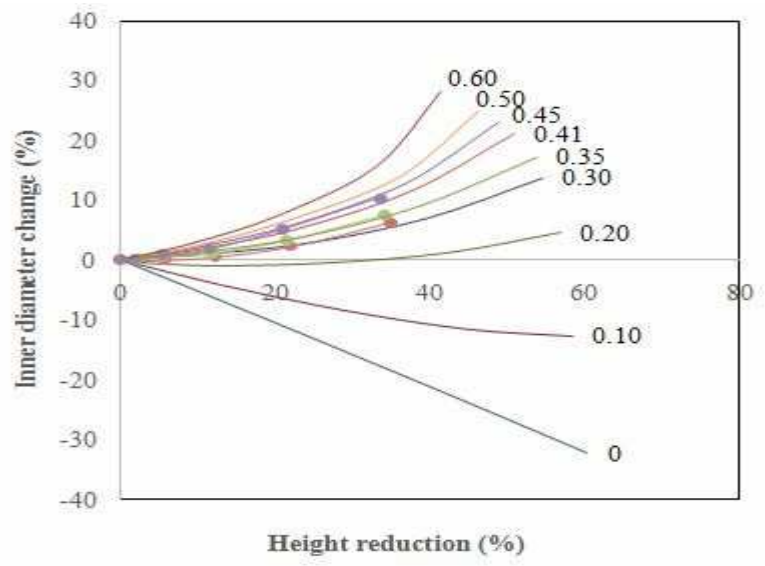

Fig.10 Friction calibration curve for AA4032 at various lubricating conditions 
At fracture point, the average deformation load requirement is obtained as $318.40 \mathrm{kN}, 303.21 \mathrm{kN}$ and $294.52 \mathrm{kN}$ with respect to lubricating conditions, emulsion oil, grease and palm oil, respectively. Comparing the results for different lubricants, one can find that the required deformation load with palm oil lubricating condition is lower. This was due to the fact that palm oil provides better capability to reduce the asperity peaks and more metal flow than grease and emulsion during deformation. Higher height reduction percentage is obtained with palm oil lubricant which can form film to achieve pretty low friction factor.

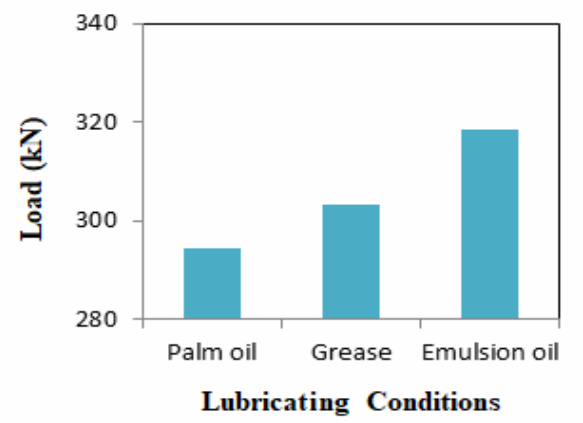

Fig.11 Effect of friction on the deformation load requirements with respect to different lubricating conditions

Figures 12 a \& b show the effect of friction factor on the induced effective strain and stress, for specimen with different lubricating conditions namely palm oil, grease and emulsion oil, respectively. In order to quantify the influence of friction, final stage of true strain with respect to lubricating conditions were considered. The results obtained for each lubricating conditions are presented separately, and allow the influence of friction factor on induced strain and stress to be investigated.
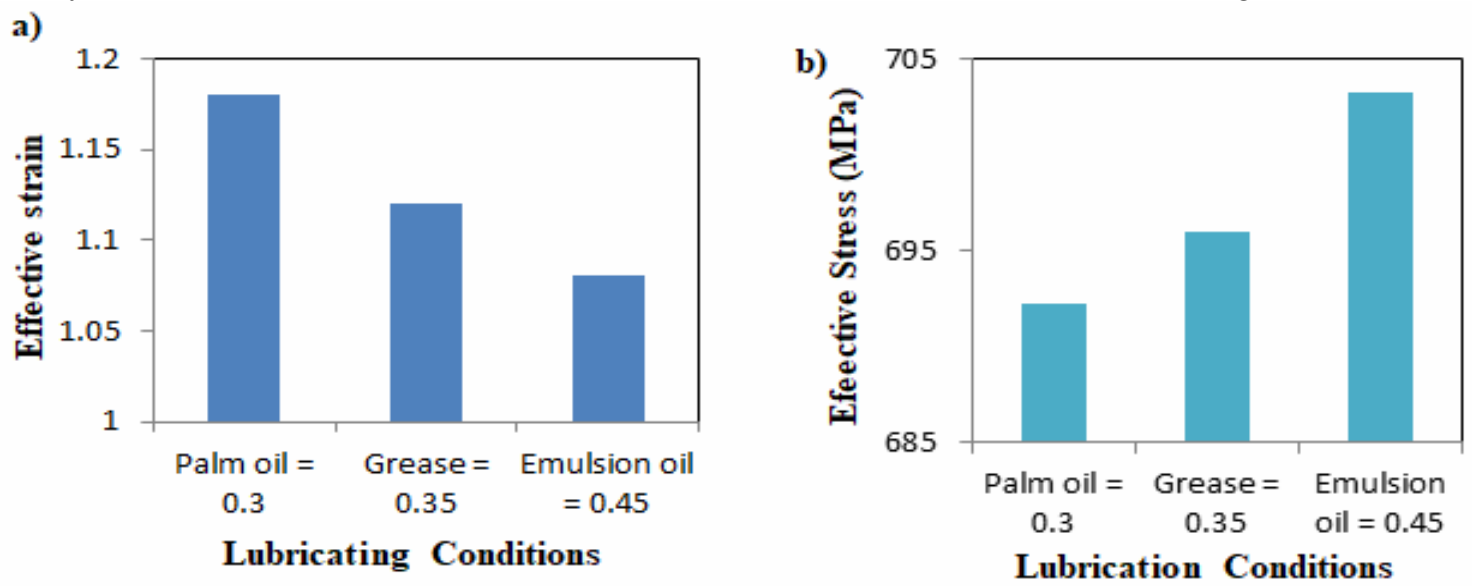

Fig.12 Effect of friction on a) effective strain, b) effective stress, for different lubricating condition

From Fig. 12 (b), the maximum effective stress is observed at lower values of effective strain and increase in friction results in a continuous increase in effective stress and decrease in effective strain. This comparison was made at each reductions of ring height. However, considering various lubricating conditions at fracture, it was observed that the height reduction increases with deformation load increases. For lower height reduction, the deformation load is low due to restriction in metal flow at the interface and consequently, the specimen fractures. In a ring compression test, the deformation load and height reduction are sensitive to interface friction. In addition, the reduction in height is the sensitive parameter, and therefore it was used to evaluate the effective stress. From Fig. 12, it can be seen that effective stress increases with increase in friction factor and this is a good indication that lubrication reduces effective stress. For the emulsion oil lubricating condition, higher friction factor and relatively lower effective stress were noted. Based on the result, lubricating condition has a significant effect on the induced effective stress and strain during forging.

\subsection{FE simulations}

The load requirement for deformation obtained from FE simulations is illustrated in Fig. 13 for specimens with various surface roughness values. To verify the relationship between friction factor and surface roughness further solid work piece were simulated between two rigid dies. The friction factor values obtained from the ring compression test (for $1.5 \mu \mathrm{m}$ surface roughness 0.50 , for $2.5 \mu \mathrm{m}$ surface roughness 0.53 and for $3.5 \mu \mathrm{m}$ surface roughness 0.55 ) were utilized for the simulation. It was clearly evident that the load required for deformation increases with increase in the friction factor for all the cases of surface roughness. The result is in full agreement with the experimental ones. 

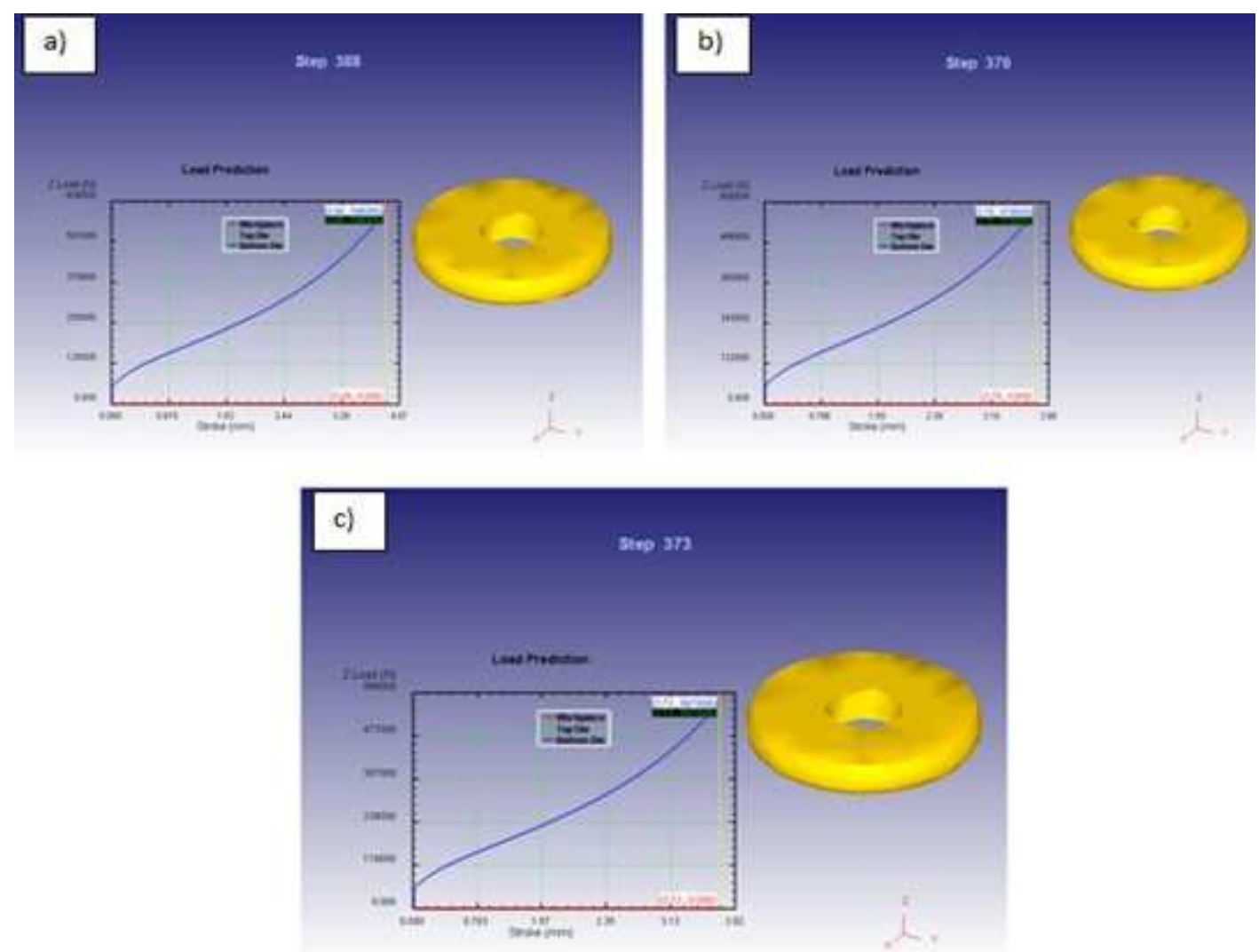

Fig.13 FE simulation load requirements with respect to friction factor for various surface roughness of (a) $1.5 \mu \mathrm{m}$, (b) $2.5 \mu \mathrm{m}$ and (c) $3.5 \mu \mathrm{m}$

Similar patterns of FE simulation results were observed for specimen deformed under different lubricating conditions. In the case, previously determined friction factor values for lubricants mainly 0.3 for palm oil, 0.35 for grease and 0.45 for emulsion oil are used in FE modeling. Obviously, the deformation load decreases with decrease in friction factor i.e. for palm oil lubricant. Lowering friction factor at the interface, results in more amount of deformation prior to fracture. In addition, variation in effective strain with respect to friction factor is determined for different surface roughness and lubricating conditions and is illustrated in Fig. 14. The effective strain is continuously decreasing with increase in the friction factor for selected surface roughness. This is due to a smaller surface roughness reduces the number of large asperities. Material has to move over to be able to flow, thus increasing the amount of strain. The FE simulation results are again in a good agreement with the experimental one. 

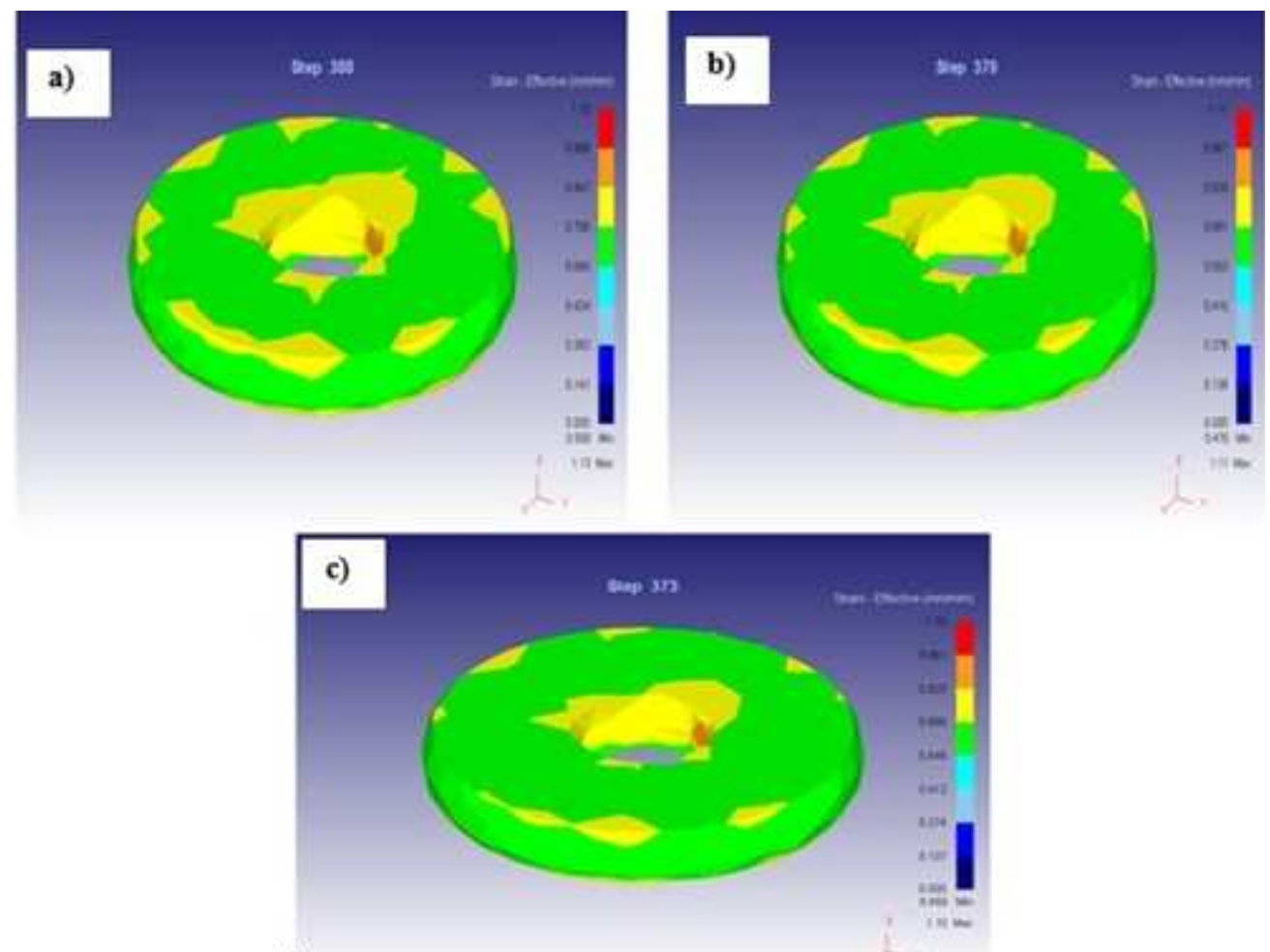

Fig.14 FE simulation results of effective strain with respect to friction factor for various surface roughness values of (a) $1.5 \mu \mathrm{m}$, (b) $2.5 \mu \mathrm{m}$ and (c) $3.5 \mu \mathrm{m}$

For lubricating conditions, similar patterns of results were observed. The reduction in height increases with the use of lubricants thereby effective strain values increases. Higher deformation was observed with the use of palm oil lubricant at the die-work interface. Figure 15 shows the effect of friction factor on the effective stress obtained using FE simulation for various surface roughnesses. Further, it was observed that the effective stress decreases with increase in friction factor. On other hand, it means that the effective stress increases with decrease in specimen's surface roughness.

In order to verify the relationship between effective stress and interface friction further with simulation, friction factor obtained at various lubricating conditions were used as in input for simulations. The effective stress decreases with increase in the friction factor for the selected lubricants.
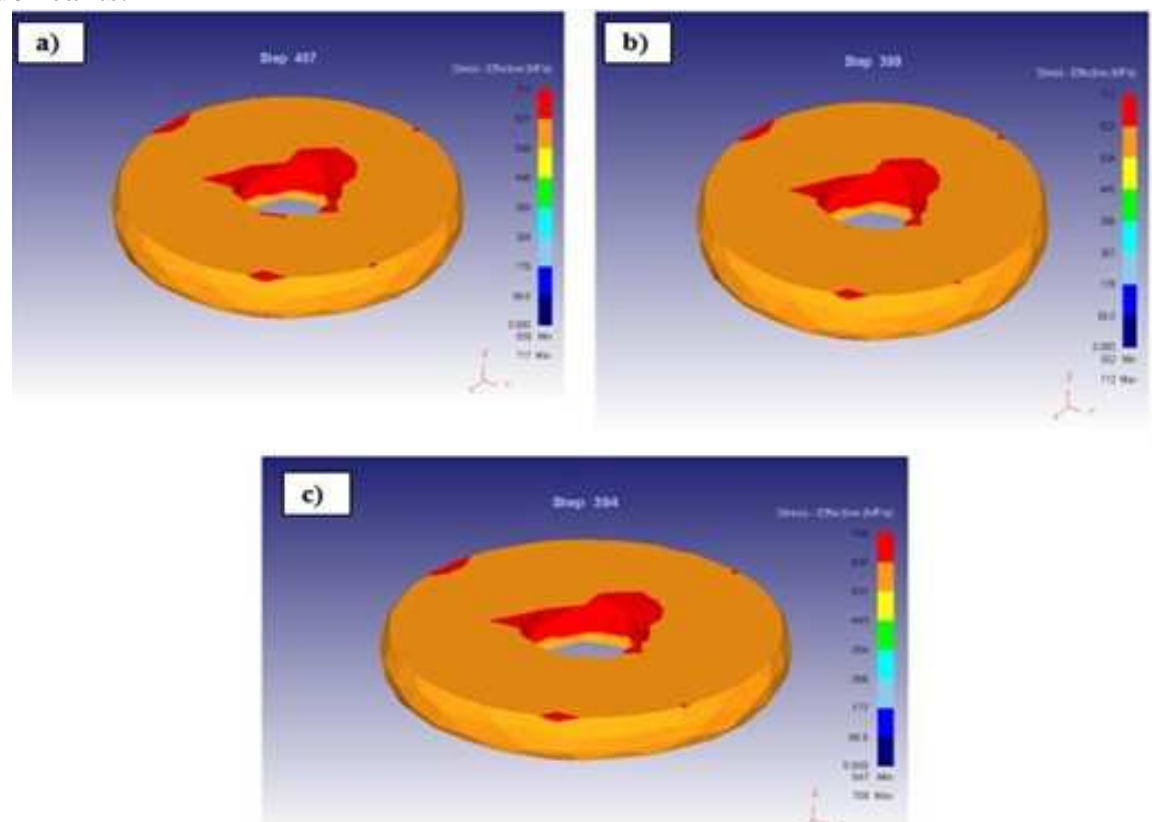

Fig.15 Effect of interface friction factor on effective stress obtained using FE simulation for various lubricating conditions 


\subsection{Validation of the result}

The specimen with geometry ratio of standard ring compression test 6:3:2 was considered for modeling as stated in the experimental procedure, and subsequently deformation test was carried out by using DEFORM 3D software. The simulation was carried out at different friction factor and height reductions that were obtained from ring compression experiment for various surface roughness and lubricating conditions. The effects of interface friction factor on load requirements, effective strain and stress at various surface roughness and lubricating conditions can be validated by comparing the simulation results with that of the results found out by the ring compression experiments and presented in Table 3.

Table 3 Comparison between ring compression test and FE simulation results for different friction factor

\begin{tabular}{|l|l|c|c|c|c|c|c|c|c|}
\hline \multirow{2}{*}{ Conditions } & \multicolumn{2}{|c|}{ Parameters } & \multicolumn{2}{c|}{$\begin{array}{c}\text { Experimental } \\
\text { Result }\end{array}$} & \multicolumn{2}{|c|}{$\begin{array}{c}\text { SE Simulation } \\
\text { Results }\end{array}$} & \multicolumn{2}{c|}{ Mean Error (\%) } \\
\cline { 2 - 11 } & $\begin{array}{c}\text { Friction } \\
\text { factor }\end{array}$ & $\begin{array}{c}\text { Height } \\
\text { reduction } \\
(\mathrm{mm})\end{array}$ & $\varepsilon_{\text {eff }}$ & $\begin{array}{c}\sigma_{\text {eff }} \\
(\mathrm{MPa})\end{array}$ & $\varepsilon_{\text {eff }}$ & $\begin{array}{c}\sigma_{\text {eff }} \\
(\mathrm{MPa})\end{array}$ & $\begin{array}{c}\delta \text { for } \\
\sigma_{\text {eff }}\end{array}$ & $\begin{array}{c}\delta \text { for } \\
\varepsilon_{\text {eff }}\end{array}$ \\
\hline \multirow{2}{*}{$\begin{array}{l}\text { Surface } \\
\text { roughness }\end{array}$} & $1.5 \mu \mathrm{m}$ & 0.50 & 3.88 & 1.10 & 706.40 & 1.13 & 706 & 0.06 & 2.7 \\
\cline { 2 - 11 } & $2.5 \mu \mathrm{m}$ & 0.53 & 3.79 & 1.06 & 709.64 & 1.11 & 701 & 1.35 & 4.7 \\
\cline { 2 - 11 } & $3.5 \mu \mathrm{m}$ & 0.55 & 3.79 & 1.02 & 714.24 & 1.10 & 700 & 1.99 & 7.8 \\
\hline \multirow{5}{*}{ Lubricants } & $\begin{array}{l}\text { Palm } \\
\text { oil }\end{array}$ & 0.30 & 4.07 & 1.18 & 692.24 & 1.25 & 676.6 & 2.25 & 5.9 \\
\cline { 2 - 11 } & Grease & 0.35 & 3.99 & 1.12 & 696.04 & 1.19 & 687.4 & 1.24 & 6.3 \\
\cline { 2 - 11 } & $\begin{array}{l}\text { Emulsi } \\
\text { on oil }\end{array}$ & 0.45 & 3.94 & 1.08 & 703.30 & 1.14 & 693.8 & 1.35 & 5.6 \\
\hline
\end{tabular}

The absolute mean error was determined using equation as $\delta=\left|\frac{V_{F E P}-V_{E X P}}{V_{E X P}}\right| 100 \%$ where $\mathrm{V}_{\mathrm{FEP}}$ is FE predicted value and $\mathrm{V}_{\mathrm{EXP}}$ is experimental value. Accordingly, the maximum mean error for effective strain requirement is $7.8 \%$ and for effective stress is $3.56 \%$ which are less than $10 \%$ and within an acceptable range. This shows that the experimental values of ring compression test is in a better agreement with the FE simulation results which validates the work. In addition, from the mode of patterns of result variation for both approaches, it is clear from the Table 3 that for all surface roughness and lubricants, the effect of friction factor on experimental load, effective strain and stress agrees well with FE simulation predictions at the final stage of the fracture where no large deformation happens.

Finally, using the above concepts, effects of various lubricant and surface roughness on interface friction, palm oil is found to be suitable lubricant for successful forging AA4032 alloy as it results in reduced deformation load requirement, increased induced effective strains and stresses and relatively uniform metal flow between die-work pieces interface. Moreover, among the selected lubricants palm oil possess good lubrication capability with interface friction factor of 0.30. On other hand, Peterson et al. (1998) correspondingly, justified that molybdenum disulphide act as a good lubricant with the friction factor value of 0.32 in which commercial aluminum has been used as base material.

\section{Conclusions}

Based on the results obtained from investigation of friction behavior using combined approach of ring compression test and FE simulations under various lubricating conditions, the following conclusions have been drawn:

- The friction factor for forging AA4032 alloy metal was determined for different surface roughness values and it increases with increase in the roughness of the surface. This is mainly due to presence of higher surface asperity peaks on the metals which restricts the flow of metal at the interface between die-work for specimens with increased surface roughness values.

- It was observed that the contraction of inner diameter, mushrooming, was increased with increase in the surface roughness, whereas, the amount of deformation (height reduction) was decreased with increase in the roughness. As a result, the smoother surface roughness of the metal appears to be suitable surface condition value for working AA4032 alloy.

- The use of lubricants during forging has reduced the deformation load requirement and effective stress and increased the effective strain which may be suitable for the required level of industrial applications.

- Among lubricants employed, palm oil is found to be a suitable lubricant for successful forging of AA4032 alloy as it results in a minimum deformation load requirement, induced effective stress and more metal flow between die-work pieces.

- FE simulations has provided detailed and effective results in the analysis of deformation load requirements, effective strain and stress and geometry changes for different experimental conditions, which are in a good agreement with the 
experimental results. Thus, integrating ring compression test with FE simulation is simple and effective tool to evaluate the friction behavior of metals.

\section{Nomenclature}

FE - Finite element

$\mathrm{FF}$ - Friction factor

SR - Surface roughness

DEFORM - Design environment for metal forming

\section{Acknowledgement}

The authors would like to thank Adama Science \& Technology University for funding this research work.

\section{References}

Bay, N., 1994, The state of the art in cold forging lubrication, Journal of Material Process and Technology, Vol. 46, pp.19. https://doi.org/10.1016/0924-0136(94)90100-7

Camacho A.M., Torralvo A.I., Bernal, C. and Sevill, L., 2013, Investigations on friction factors in metal forming of industrial alloys, Procedia Engineering, Vol. 63, pp. 564-572. https://doi.org/10.1016/j.proeng.2013.08.240

Cisson, M.C., Rausina, G.A. and Stonebraker, P.M., 1996, Human health and environmental hazard characterization of lubricating oil additives, Lubrication Science, Vol. 8, pp.145-177. https://doi.org/10.1002/ls.3010080205

Dutton, R. E., Seetharaman, V. and Goetz, R. L., 1999, Effect of flow softening on ring test calibration curves, Materials Science and Engineering, Vol. 270, No. 2, pp. 249-253.

DePierrie, V. and Gurney, F., 1974, A method for determination of constant and varying friction factors during ring compression tests, Transactions of the American Society of Mechanical Engineers: Journal of Lubrication Technology, Vol. 96, pp. 482-488. https://doi.org/10.1115/1.3452015

Fereshteh-Saniee, F. and Fatehi-Sichani, F. 2006, An investigation on determination of flow curves at room temperature and under forming conditions, Journal of Materials Processing Technology, Vol. 177, pp. 478-482. https://doi.org/10.1016/j.jmatprotec.2006.04.043

Fereshteh-Saniee F., Pillinger I. and Hartley P., 2004, Friction modeling for the physical simulation of the bulk metal forming processes, Journal of Material Processing Technology, Vol. 153-154, pp 151-156. https://doi.org/10.1016/j.jmatprotec.2004.04.217

Isogawa, S., Kimura, A., and Tozawa, Y., 1992, Proposal of an evaluating method on lubrication, CIRP Annals - Manufacturing Technology, Vol. 41, pp 263-266. https://doi.org/10.1016/S0007-8506(07)61200-1

Male, A.T. and Cockcroft, M.G., 1965, A method for the determination of the coefficient of friction of metals under condition of bulk plastic deformation, Journal of the Institute of Metals, Vol. 93, pp. 38-46.

Narayanasamy, R. and Pandey, K.S., 1997, Phenomenon of barreling in aluminum solid cylinders during cold upset-forming, Journal of Materials Processing Technology, Vol.70, pp.17-21. https://doi.org/10.1016/S0924-0136(97)00035-6

Oh, S., Wu, W., Tang, J. and Vedhanayagam, A., 1991, Capabilities and application of FEM code DEFORM: the perspective of the developer, Journal of Materials Processing Technology, Vol. 27, pp. 25-42. https://doi.org/10.1016/0924-0136(91)90042-D

Peterson, S.B., Martins, P.A.F. and Bay, N. 1998, An alternative ring-test geometry for the evaluation of friction under low normal pressure, Journal of Materials Processing Technology, Vol.79, No. 1-3, pp.14-24. https://doi.org/10.1016/S09240136(97)00448-2

Peterson, M. B., and Ling, F. F., 1966, Friction and lubrication at extreme pressures: symposium on friction and lubrication in metal processing, American Society of Mechanical Engineers, pp. 39.

Rao, J.B., Syed Kamaluddin., Appao Rao, J., Sarcar, M.M., and Bhargava, N.R.M.R., 2009, Finite element analysis of deformation behavior of aluminum-copper alloys, Materials and Design, Vol.30, No. 4, pp.1298-1309. DOI: 10.1016/j.msea.2003.12.029

Rajesh E. and Siva-Prakash M., 2013, Analysis of friction factor by employing the ring compression test under different lubricants, International Journal of Scientific and Engineering Research, Vol. 4, No. 5, pp. 1163-1171.

Shahriari D., Sadeghi, M.R., Ebrahimi, G.R. and Kim, K.T., 2011, Effects of lubricant and temperature on friction coefficient during hot forging of nimonic 115 superalloy, Journal of Material Engineering and Performance, Vol. 49, pp 375-383. DOI: 10.4149/km_2011_5_375

Semiatin, S.L., 1998, Handbook of Metals: Introduction to Forming and Forging Processes. ASM Handbook Committee, USA. Vol. 14, 9th Edition

Sofuoglu, H. and Rasty, J., 1999, On the measurement of friction coefficient utilizing the ring compression test, Tribology International, Vol. 32, pp 327-335. https://doi.org/10.1016/S0301-679X(99)00055-9

Wogaso, D., Davidson, M.J. and Khanra, A.K., 2014, Friction factor evaluation using experimental and finite element methods for Al-4\%Cu preforms, Journal of Materials Engineering and Performance, Vol. 23, No. 8, pp. 3068. DOI: 10.1007/s11665-014$1063-\mathrm{z}$ 


\section{Biographical notes}

Desalegn Wogaso completed his doctorate degree at the age of 31 years in Mechanical Engineering from National Institute of Technology, Warangal, India. He iscurrently assistant professor \& a researcher in the field of Mechanical Engineering at Addis Ababa Institute of Technology, Addis Ababa, Ethiopia. Over the last ten years, he has been worked as researcher, director for research \& technology transfer and scientific director at a public university in Ethiopia. He has published more than 15 papers in peer reviewed reputable journals and few more are under different stages of revision. His research concerns are development, characterization and modeling of advanced materials and their behavior under different loading conditions, advanced processes and technologies for the applications of $21^{\text {th }}$ century manufacturing industries.

Mohmmed Hamda is currently a lecturer in Mechanical Engineering department, Kombolcha Institute of Technology, Ethiopia. He has been working as a teacher, researcher and supervising undergraduate students. His research focus areas are on manufacturing processes, methods and materials. Mohammed is a talented researcher, a dedicated youth leader in his community in science and technology education. 